\title{
TEACHING AND LEARNING
}

\section{Cultivating Business Intelligence through Online Workshops: A Case Study}

\author{
NORA B. WOOD \\ Emory University, Atlanta, GA \\ nora.wood@emory.edu \\ SAIRA RAZA \\ Emory University, Atlanta, GA \\ saira.raza@emory.edu
}

\begin{abstract}
Column Introduction Many librarians are looking for ways to improve their delivery of online instruction during the pandemic. Nora B. Wood and Saira Raza of Goizueta Business Library at Emory University provide a detailed look at the complexity of transitioning a for-credit workshop series, Business Essentials, to delivery through the University's learning management system, Canvas, in their article below. Large numbers of business undergraduates take Business Essentials during their junior year, so it was critical to develop an efficient workshop management process as well as excellent content. Their case study describes the iterative process of creating the asynchronous Business Essentials course. Their lessons learned can help other librarians looking to implement similar instruction programs at their institutions or provide guidance for various aspects of online course delivery. Sandy Miller and Christina Sheley, Column Editors
\end{abstract}

Like many business librarians at other universities, the librarians at Emory University's Goizueta Business Library (GBL) have long sought to integrate business intelligence instruction into the undergraduate curriculum in an effort to enhance students' critical thinking and creative problem-solving skills. Unsurprisingly, much of this type of instruction came in the form of one-shot sessions taught at strategic points during the semester; however, most of these sessions were targeted to specific class assignments and therefore did not allow the librarians to address broader and more baseline business intelligence needs.

As a result of strong relationships with the Goizueta BBA Program Office, the opportunity arose for targeted, in-depth research sessions to be built into the undergraduate curriculum at a more fundamental level. Namely, the business librarians were offered the chance to build business intelligence workshops that would be offered to undergraduate business students as a component of their junior year seminar. Students who attended four sessions would receive a business research certificate as incentive to attend these workshops over some of the other offerings in the wide pool of junior seminar sessions.

The Business Essentials workshops first came in the form of multiple in-person sessions that covered a variety of topics from marketing to entrepreneurship to finance. Several workshops also centered on specific databases and their utility. Over time, class popularity and the small size of the available teaching classrooms inspired the business librarians to begin brainstorming opportunities to expand the reach of Business Essentials beyond the traditional in-person setting. 
Ticker: The Academic Business Librarianship Review, 5:2 (2021)

http://dx.doi.org/10.3998/ticker.16481003.0005.202

(C)2021 Nora B. Wood and Saira Raza

\section{The Problem/Opportunity}

In 2016, the Business Essentials classes were generally well-attended; however, there continued to be issues at the end of the semester with dozens of students in need of credit for their junior seminar and few opportunities to earn it. The GBL team experimented with various strategies including scheduling repeat classes for up to 25 students and conducting classes in larger classrooms at the business school with up to 65 students. In particular, students in the larger classes tended to be less engaged, and a couple were not shy about their level of disinterest and left early! While the content and delivery were the same as the successful smaller classes, the formula simply did not work well in these new conditions.

The same year, after many years of using Blackboard, Emory University transitioned to a new learning management system, Canvas. Having attended a training on how to use the new system, the BBA liaison started experimenting with the idea of creating an online Business Essentials class to meet the needs of both the students who need a more flexible class structure and the business librarians who were increasingly stretched by the end-of-semester Business Essentials demand. She created a Sandbox course for her colleagues to join her in learning the features and capabilities of Canvas. Although there were many possibilities, it was clear that not every Business Essentials class would be a good fit, especially given the team's limited experience with online teaching.

\section{Developing the First Online Business Essentials Class}

To start, the team reviewed the existing courses and considered what kind of content makes the best sense to translate to an online format. Business Essentials courses tend to have two distinct approaches. In some courses, such as Research the Market for Your Business Startup, students learn conceptual approaches to research and may use several resources in a short period of time. In others, students take a deep dive in a specific resource to learn how to make the most of its features and capabilities. In all inperson classes, students are expected to participate in both group and individual work, using the resources directly, and reporting their results as part of a class discussion. When students work on group projects related to conceptual research and using multiple resources, their contributions to the group discussion tend to be more varied and creative. However, when they are learning to use a specific database, it is easier to create deliverables that are either correct or incorrect.

While both approaches presented challenging considerations, offering an in-depth look at a single database proved to be an easier way to leverage the visual and self-directed nature of asynchronous online learning. The team decided to start with the Business Essentials class Become a Business Source Complete Rock Star, which featured measurable learning outcomes, including the ability to perform concise searches for articles and company profiles. These learning outcomes were ideal for an online class because of two important factors. First, there were specific steps that could be easily explained and demonstrated on slides. Second, it was possible to create a clear set of deliverables that were easy to grade and adequately demonstrated that students had achieved the learning outcomes. For example, students were given realistic questions about finding specific articles, and they demonstrated their learning by uploading PDF copies of the articles. Simple questions that could be phrased as a multiple choice were easily graded using Canvas's automation tool. The lessons were scaffolded by level of difficulty, culminating in a final multi-step assignment in which the students created and executed a Boolean search and then submitted a bibliography of five relevant sources they found in their search.

Having novice-level experience in developing online content, the business librarians leveraged the expertise of Emory Libraries' Academic Technology Support team to understand which features of Canvas 
Ticker: The Academic Business Librarianship Review, 5:2 (2021)

http://dx.doi.org/10.3998/ticker.16481003.0005.202

(C)2021 Nora B. Wood and Saira Raza

would be most helpful in creating a positive learning experience for the students. Emory University's Center for Faculty Development and Excellence (CFDE) instructional design experts were also an invaluable resource for exploring the nuanced challenges of developing a logical and meaningful flow for online content. After first identifying the specific skills the students ought to know by the end of the course, the instructor then had to determine in which order these skills should be presented and what kinds of assignments and/or quizzes might work to demonstrate that students had achieved the learning outcome. The final outline of the course fit neatly into Canvas's module formats and was designed to take ninety minutes to complete, the same length of time as the in-person classes (see Appendix for course outline).

By the writing of this case study, the course has had five iterations and each one has revealed new opportunities to improve, both in terms of impact and efficiencies. Overall, the business librarians identified several important considerations in developing online business intelligence courses.

Content Creation. As with all instruction preparation, it is important to clearly identify and communicate the specific learning outcomes the students can expect by the time they finish the course. When designing the modules, be sure to focus each module on one specific learning outcome and provide step-by-step instructions with screenshots and notations. It is also helpful to clearly identify in the presentation where students complete assignments and quizzes to align with the content they just covered.

Grading and Class Administration. Since online classes tend to be very popular and can accommodate a large number of students, it is vital to ensure an easy grading process on the back-end for the instructor. Leveraging quiz formats that allow automatic grading, such as true/false and multiplechoice questions, is one way to save time and frustration when grading. When it comes to assignments, it helps to create tasks that have specific uploads that are clearly correct or incorrect at first glance. Canvas's SpeedGrader feature allows the instructor to see the uploaded PDF, JPG, or Word file on the screen without having to download the items first and submit a grade on the same screen, while scrolling to the next student's assignment with just one click. For large classes, the business librarians found it effective to divide the grading responsibilities across the team rather than leaving everything for just the instructor.

Managing Student Expectations. For in-person Business Essentials classes, students received credit for simply showing up and participating in the 90-minute session. However, it was more challenging to ensure students experienced the same level of rigor without supervision. To ensure that students actively engage in the content and do not "blow it off," clearly articulating the expected level of performance to earn credit is essential. For this Business Essentials course, the instructor required students to complete all the assignments and achieve an overall grade of $70 \%$. This information is messaged in the landing page of the class as well as via periodic announcements while the class is open to the students. Students are also offered the opportunity to resubmit quizzes and assignments as needed to meet the $70 \%$ grade requirement. Canvas, like other learning management systems, provides opportunities to share comments with students to give them extra tips or suggestions for corrections as well. 
Ticker: The Academic Business Librarianship Review, 5:2 (2021)

http://dx.doi.org/10.3998/ticker.16481003.0005.202

(C)2021 Nora B. Wood and Saira Raza

\section{Creating Conceptual Seminars}

After a few semesters of successfully teaching resource-specific Canvas courses, the business librarians decided to broaden the scope of the online Business Essentials offerings and create a class more conceptual in nature. Specifically, the librarians developed a course centered on career research that utilized multiple databases licensed by the library and covered a variety of career-related concepts and skills development. This class was adapted from an in-person session that one of the business librarians had taught at a previous institution. It was designed to introduce students to new resources and show them how to explore different applications of resources they might have used in the past.

It became clear through the creation of this course that several key principles and practices should be observed in order to develop the most cohesive and coherent curriculum for a class of this kind. First, the librarians realized that if they were going to introduce multiple resources in a short workshop, only limited components of each resource could be covered rather than the full breadth and depth. Therefore, rather than attempting to capture every possible usage of a database, the focus needed to be centered on smaller, more digestible attributes and quick takeaways. For example, one module of this course introduces students to the database First Research and shows them how to quickly and conveniently develop a list of call prep questions that can be used at career fairs and in interview preparation. The same module briefly discusses some of the other applications of the database, but clearly focuses on call prep questions as the key takeaway. This approach, while not comprehensive in nature, helps reduce the possibility of confusion and distraction while still allowing students to begin to explore databases that were previously unfamiliar to them.

Secondly, librarians can save time during instructional design and development by highlighting new features of previously explored databases. In this course, for instance, students are shown how to utilize LinkedIn in a new way to discover potential networking opportunities. Specifically, one module of the class features LinkedIn's alumni tool and teaches students how to identify and connect with current evening and modular MBA students who work in industries and companies of interest to them. The business librarians knew that the students attending the workshop had already been required to create a LinkedIn profile as part of a core business school class, but were confident that few, if any, had tapped into this particular feature of LinkedIn. This approach of revealing new uses of known resources allows students to broaden their knowledgebase, but does not force the librarian to spend too much time demonstrating the navigation of that resource. Of course, assuming that students have already used a particular resource can be risky and must be done thoughtfully in order to be successful.

\section{Logistics}

As with any new undertaking, finding the smoothest and most streamlined process for handling the logistics of the online workshops took time, patience, and a lot of trial and error. By the third year, however, many of the kinks had been worked out, and the main logistical considerations fell into three primary categories: timeline, registration, and grading.

After years of teaching both in-person and online Business Essentials classes throughout the semester, the business librarians decided to compress the sessions into a one-month period each semester rebranded as Business Essentials Month (BE Month). April and November were chosen after careful evaluation of the data indicated that these months consistently had the highest levels of student participation. The online classes had previously been open for staggered two-week periods throughout the semester, but with the introduction of the new "BE Month", the business librarians decided to open all 
Ticker: The Academic Business Librarianship Review, 5:2 (2021)

http://dx.doi.org/10.3998/ticker.16481003.0005.202

(C)2021 Nora B. Wood and Saira Raza

online classes concurrently for a three-week period so students could complete any or all of the sessions as their schedules allowed. Having a three-week window gave the students plenty of time to complete each workshop, and the librarians found that this slightly-extended timeframe also allowed for any technical or database issues to be resolved.

Further, the business librarians needed to determine the best process, tools, and timeline for getting students registered and uploaded to classes. The class descriptions were already being housed in the Goizueta BBA portal. After several semesters of experimenting with a variety of survey tools, the business librarians chose to rely on the University's subscription to Qualtrics to create registration forms that were included in these class descriptions. Then the librarians needed to consider the timeline for registration: should students be required to register in advance of the class starting or should they be admitted on a rolling basis throughout the duration of the workshop? After much back-and-forth discussion and a few semesters having students register in advance, the librarians concluded that an open, rolling registration would be the best option. While this type of registration does necessitate that one person uploads new students to Canvas every day, it greatly reduces the number of one-off emails from frantic students who missed the deadline and are asking for special permission to be added to a class. Given the volume of this type of request, it simply made more sense for the librarians to circumvent the issue altogether by providing open registration.

Scheduling a reasonable timeline for grading all the workshop content was and continues to be a critical component of the logistics puzzle. Because the Business Essentials online workshops count for credit and toward a business research certificate, the business librarians need to have grading completed in enough time for credit to be uploaded and certificates to be made and personalized before the semester ends. This is a tight turnaround, but there are several tricks to speed along the process, which will be discussed in greater detail in the Challenges and Adjustments section below.

\section{Success Factors}

As the business librarians had hoped, the online Canvas courses mitigated a number of challenges that the in-person classes had presented. These hurdles ranged from logistical to conceptual in nature, and their successful elimination helped prove that the online format could be just as effective as the inperson.

Logistical Successes. First of all, the issue of small classroom sizes disappeared with the online format. Instead of attendee numbers ranging between 10 to 25 per in-person class, the business librarians were able to engage with anywhere between 40 and 80 students per online Canvas session. This is a two-fold success, as the students are often desperate by the end of the semester to squeeze in all the required junior seminar courses and the business librarians also want their content to reach a broader audience.

Additionally, the online format allows the librarians to leverage online instructional technologies and internal resources to create more interactive activities. Specifically, these classes allow the librarians to work extensively with the Canvas support team and to utilize tips and tricks from the instructional design team to develop thoughtful and creative activities that can truly help expand student comprehension.

Further, in the online format, it is easier to assess actual student comprehension, since students are graded on individual assignments rather than simply receiving credit for attendance. During in-person sessions, the business librarians do not grade in-class activities, rather relying on a subjective feedback 
Ticker: The Academic Business Librarianship Review, 5:2 (2021)

http://dx.doi.org/10.3998/ticker.16481003.0005.202

(C)2021 Nora B. Wood and Saira Raza

form in which students share their perceived (rather than actual) mastery of the class content. Meanwhile, the Canvas format allows for multiple submissions and personalized comments on assignments, meaning that librarians can offer specific, assignment-based feedback and students have the opportunity to correct errors and learn from their mistakes.

Student Engagement Successes. Interestingly, despite the absence of in-person contact, the online Canvas courses also allow for a depth of student engagement rarely seen in classroom settings. Because the students have to "prove their attendance" by completing short quizzes and activities, they necessarily become more involved with the content. Correspondingly, the librarians are able to gauge each student's comprehension of the topic and offer tailored feedback to help guide and instruct when confusion arises. This also serves as a form of assessment wherein the librarians can identify if multiple students are having the same issues and can adjust assignments or directions as needed. During inperson sessions, it can be difficult to see where the problem areas actually lie, but by having multiple graded assignments, it quickly becomes obvious when something is unclear or needs to be better explained.

Furthermore, the business librarians began to notice that students are far more forthcoming with helpful criticism and feedback in the Canvas classes than they are during in-person sessions. In fact, the business librarians have noticed a depth and thoughtfulness to responses that far exceed that of the responses gathered from in-person classes. The most likely explanation: by the time they get to the feedback form, the students are already used to the format of answering questions online, so there is less hesitation to provide real and authentic answers. Also, the online format provides a level of distance from the librarians which might encourage them to be more honest and straightforward with feedback than in a class where the librarian is standing right in front of them.

\section{Challenges and Adjustments}

No new venture is completely without its challenges, of course, and transitioning Business Essentials courses to an online format presented some difficulties that the librarians had not encountered during the in-person sessions. These complications do not by any means negate the successes of the online transition, but they highlight some considerations that a librarian seeking to create online workshops should consider.

Logistical and Technical Challenges and Considerations. First of all, the initial development of courses can be quite lengthy and time-consuming. Even converting existing classes into online modules requires a careful reworking of content into digestible components. For instance, showing students how to set up an account in a new database might be a five-minute exercise in an in-person class, but this same task can turn into a detailed step-by-step process with multiple screenshots in a PowerPoint presentation or a video tutorial that requires scripting and careful editing before it can be incorporated into an online class. On the flip side, once a class is created and uploaded the first time, it only requires periodic updates to keep it current and ready for the next semester. Most typically, these updates need to be made due to any database navigation, content, or interface changes. In selecting a database to teach in an asynchronous virtual environment, more established database products may provide better options for experimentation, as they undergo updates and interface changes less frequently.

Similarly, the process of grading the work of $40-80$ students (or however many sign up) can be cumbersome and quite time-consuming. For several semesters, the Goizueta Business School librarians' 
Ticker: The Academic Business Librarianship Review, 5:2 (2021)

http://dx.doi.org/10.3998/ticker.16481003.0005.202

(C)2021 Nora B. Wood and Saira Raza

timeline of grading and uploading credit for the students became quite lengthy, which created further difficulties for the stakeholders who needed complete lists of participants before they could move forward with the next stage of their own work (e.g., creating the business research certificates, etc.). At your own institution, consider taking steps to speed up the process of grading, such as developing assignments that grade themselves within the online platform (e.g., multiple choice quizzes) or having volunteers help with the grading to reduce turnaround time. The business librarians at Emory decided to share the grading load across the team, including library student assistants, to ensure that the full burden did not rest on just one or two librarians. Another method of easing the burden is to grade assignments on a rolling basis to prevent a buildup of grading that needs to be completed within a compressed time period.

Every semester the business librarians continue to experiment with better and more efficient ways to market the online classes and streamline the sign-up process. Since these courses are not managed through the university registrar, the librarians must collect the names of the attendees and manually add them to the course. Inevitably, there are a few errors that result in several back-and-forth emails to ensure students are enrolled in the class properly. One strategy that has helped mitigate this is to keep the course open during the entire "Business Essentials season" rather than only for one- or two-week periods. It also helps to coordinate the sign-up process with the program office and ensure that everyone is one the same page about the policies and processes for signing up and receiving credit.

Further, with any online work, there are going to be technical challenges that arise. Sometimes, these are small inconveniences that clear themselves up with time (e.g., a database undergoing routine maintenance and being inaccessible for a short period), but other times these can greatly impact the entire progress of the class (e.g., a database changing its whole interface or navigation). In order to mitigate the disruption of this latter type of technical difficulty, the librarian organizing the class must be flexible and willing and able to change assignments and activities on the spot. Sometimes this means foregoing a particular assignment altogether for a semester or coming up with a quick substitute that the students can easily complete. For however long the online workshop is open to students, then, the librarian must be easily accessible and able to address problems and questions quickly when they inevitably arise.

Communication Challenges and Mitigations. Setting clear expectations for the program office, the students, and even the library team itself can be perhaps the greatest hurdle of all when developing an online workshop or workshop series. Luckily, this challenge can be mitigated with clear and careful communication, but the structure and form that this communication takes should be established early on to avoid unnecessary confusion.

Specifically, in order to minimize miscommunication from the start, it is important to set up routine meetings with stakeholders to ensure that everyone is on the same page. If there are multiple librarians or departments involved in the process, it is strongly recommended that one person serves as the primary lead who will plan, schedule, and provide structure and agendas for meetings. That person can then become the conduit between departments and stakeholders and deliver information as needed in order to reduce redundancies and communication missteps.

Establishing clear communication with students from the time of registration up through completion of the grading is also critical for minimizing confusion. The first few semesters that the Goizueta Business School librarians taught online classes, there was a deluge of one-off email questions regarding the registration process, timeline of grading and credit, and various other "housekeeping" concerns. Although impossible to eliminate completely, the number and frequency of these emails can be greatly reduced by 
Ticker: The Academic Business Librarianship Review, 5:2 (2021)

http://dx.doi.org/10.3998/ticker.16481003.0005.202

(C)2021 Nora B. Wood and Saira Raza

providing thorough descriptions and explanations at multiple stages in the process and throughout platforms (e.g., on the library and program office websites and in Canvas). The librarians should also provide periodic updates via the Announcement tool in Canvas when numerous students seem to have the same types of questions and concerns.

And lastly, careful communication with the library team is invaluable to making the process as streamlined as possible. Consider in advance some key questions: who is in charge of setting up registration and uploading students to the online classes; who is responsible for grading and granting students credit; who has updated the library website with the most current information about the workshops; who needs copies of student participant information? Establishing the answers to these questions from the beginning will help simplify the process and reduce the number of roadblocks along the way. Proper documentation with accompanying screenshots, directions, and tips for how to complete these processes can also serve as an effective back-up in the event that the person responsible for completing any given task is unexpectedly unavailable.

\section{Assessment}

One great advantage of the online format is the way in which the business librarians could solicit feedback on the course. For in-person classes, there was no way to ensure that every student completed the feedback form provided. Moreover, the responses tended to be lean as students were anxious to leave the classroom and get to their next commitment. In contrast, student responses to the feedback form for online classes were rich in content, and students appeared to be more candid with their experiences and suggestions.

A critical distinction is that, in the online class, the feedback form is posted as a quiz for which they get credit for any response. By making the feedback form a graded assignment, students felt more compelled to answer (see Appendix for feedback questions). While a formal text analysis has not been performed on the student feedback responses, the overall themes are generally positive, many students expressing their surprise at how useful Business Source Complete was to their immediate assignments. Most students appreciated that there was an online course option that allowed them to work on their own schedule and at their own pace and found that it took between one and two hours to complete. A consistent piece of criticism was that students missed the opportunity to ask questions in real time.

\section{Conclusion and Next Steps}

Over the course of online workshop instructional design and development, the business librarians have learned a great many lessons about best practices and techniques that will hopefully be of use to librarians at other institutions seeking to create their own online workshops. And as more schools expand virtual learning opportunities to accommodate new physical distancing demands of the COVID-19 pandemic, it is paramount that instructors seek to improve the experience for students and ensure that learning outcomes are not compromised. Naturally, the learning process is ongoing, and there are steps and plans in place for the business librarians to continue to streamline and improve the workshops that already exist as well as to expand into new content and topics.

One key component that will be featured in the next steps includes integrating deeper information literacy components into and across all courses. Among other skills under the broader umbrella of information literacy, these new modules will help students learn to evaluate the credibility and trustworthiness of sources as well as to understand when and how to effectively and efficiently use one 
source over another. The business librarians have long noticed that students struggle to differentiate between credible and biased sources and believe that by thoughtfully building more foundational knowledge into online workshops, the students will begin to develop the skills to make more informed research decisions.

Also, the business librarians are very interested in developing new online workshops to add to their list of Business Essentials offerings. These classes will be a combination of resource-specific and conceptual offerings that will allow the business librarians to showcase new instructional technologies and techniques that they have learned. This is an especially exciting next step for the business librarians to take to help make online workshops even more interactive and engaging.

Finally, it may be helpful in the future to conduct a formal text analysis of the student feedback. This exercise could reveal deeper insights about the effectiveness of online courses and opportunities to improve the experience for the undergraduate business students.

Through the entire process of idea generation to content creation to engaging with students and grading assignments, the Business Essentials online workshops in Canvas taught the business librarians to stretch and grow into adaptive instructors. As a result, after multiple iterations and many redirects, the path toward content development has become much more streamlined and simplified. Further, and perhaps most importantly, the students were able to develop heightened research skills in the online environment because it allowed them to engage deeply in the research process and receive personalized feedback along the way. 
Ticker: The Academic Business Librarianship Review, 5:2 (2021)

http://dx.doi.org/10.3998/ticker.16481003.0005.202

(c)2021 Nora B. Wood and Saira Raza

\title{
Appendix. Outline of "Become a Business Source Complete Rock Star"
}

- Introduction Module

- A simple introduction page that includes a YouTube video published by EBSCOhost about setting up a profile

- One assignment that touches several skills:

- Signing in

- Setting up a profile

- Conducting a search for "Goizueta Business School"

- The students submit a screenshot of the results screen which should show that they are logged into their profile and that they conducted the search

- One quiz that tests their basic knowledge of what they can expect to find in Business Source Complete and how they can display results

- $\quad$ Finding Specific Articles \& Publications

- One PowerPoint Presentation with screenshots and explanations for various techniques for finding specific articles and publications (See Figure 1.)

\section{Finding Specific Publications}

To find a specific publication in BSC, start by selecting the Publications link in the top menu

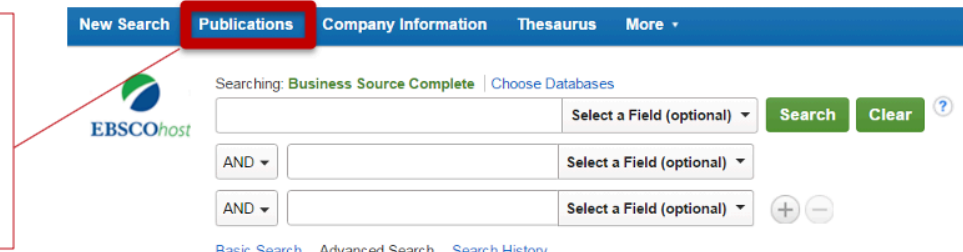

\section{New Search Publications Company Information Thesaurus More}
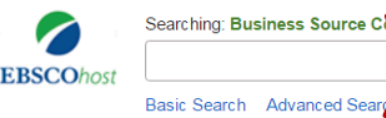$$
\text { Basic }
$$

Publications

Browsing: Business Source Complete -- Publication

\begin{tabular}{|l|l|}
\hline & Browse
\end{tabular}

- Alphabetical By Subject \& Description Match Any Words

Page: Previous Next \ABCDEFGHIJKLMNOPQRSTUVWXYZ

\begin{abstract}
Make sure you are using this box to search for the name of the publication. It's very easy to confuse this with the basic search box above it.

You can search for publications by its name, by a keyword from the subject or description, or by a keyword in the publication title. Be sure to select the appropriate radio button for your search, right below the search box.
\end{abstract}

Figure 1. PowerPoint slide explaining how to search for a specific publication. 
- Two assignments requiring students to upload a specific article based on prompts that provided only the topic and author or only the topic and publication.

- A quiz that demonstrates students know what kind of information they can expect to find in the bibliographic record of an item, how to determine if a publication is peer-reviewed or not, and how to request the full-text of an article via interlibrary loan

\section{- Searching for Company Information}

- A PowerPoint presentation describing the differences in researching private and public companies and providing screenshots and instruction for doing both types of company research

- Two assignments in which the students have to find and submit the most recent MarketLine SWOT analysis for one public and one private company

- A quiz that further evaluates their understanding of private vs. public company research

\section{- Searching for Information on Industries, Issues, and Topics}

- A PowerPoint presentation that describes the usefulness of Boolean searching and provides step-by-step instructions of the basic operators

- A link to an additional video demonstrating how to create Boolean search strings

- A quiz in which the students show their work to create a Boolean search about a specified research topic (i.e. the regulation of self-driving cars)

- An assignment to create a bibliography of five relevant results from their Boolean search created in the quiz

\section{- Reflections and Feedback}

$\circ$ A note from the instructor wrapping up the content, restating the learning outcomes, and reminding students of Emory Libraries Proper Use of Databases policies

- A feedback survey of open-ended questions for which students receive a point for any answer they provide:

- What did you gain as a business researcher by doing these activities? Do you have specific projects or interviews coming up where you can apply your new BSC skills? Be specific!

- Did this class meet your expectations? I'm totally open to your critique!

- If you have taken other Business Essentials classes, how does this online format compare to the in-classroom experience?

- To help us with future planning, please tell me approximately how long it took you to complete these activities. 